Practice Reflections

\title{
Assessing social work students on practicum at the United Arab Emirates University (UAEU): Challenges and implications
}

\section{Taghreed M. Abu Sarhan ${ }^{1}$ and Prospera Tedam ${ }^{1}$}

\begin{abstract}
The Social Work program at the United Arab Emirates University (UAEU) is the first and the only program-training students for Masters in Social Work (MSW) in the United Arab Emirates. MSW students are required to undertake 500 hours of practice in the field while Bachelor in Social Work (BSW) students are required to complete 400 hours of practicum. This paper outlines both BSW and MSW practicum courses and examines the assessment tools and methods that contribute to students' readiness for practice upon qualifying. The authors explore the framework in practicum settings in the UAE and critically reflect on the challenges of the current assessment methods in preparing professional social workers for practice upon graduation. The absence of service user contribution in the assessment process is considered a major disadvantage to the holistic development of social workers in the UAE and will be examined. Significantly, the two authors who are female address the issue of gender within the context of assessment due to gender segregation in field practicum linked to the cultural and religious requirements in the UAE. The paper concludes with recommendations to improve the assessment of social work students at both BSW and MSW levels at the United Arab Emirates University.
\end{abstract}

Keywords: Social Work; Practicum; UAEU; Assessment methods; BSW; MSW

1. Social Wellbeing Dept. United Arab Emirates University (UAEU)

Address for correspondence: abusarhan@uaeu.ac.ae

Date of first (online) publication:

31 J. of Practice Teaching \& Learning 17(3), pp.31-46. @ w\&b 


\section{Introduction}

Globally, social work students undertake varying periods of practicum as part of their training at both undergraduate and graduate levels. In the United Arab Emirates University (UAEU) the practicum component is 400 and 500 hours respectively. The BSW practicum is made up of 200 hours in a school and 200 hours in any health or social care organization.

There is yet no shortage of practice placements for students however there is a growing anxiety about how students are assessed on placements.

In this paper, we begin by providing a context of the development of social work education in the Arab world and the United Arab Emirates in particular. A brief discussion about social work practice in the UAE will be undertaken after which we will proceed to outline the social work programme at UAEU. An exploration of the tools used to assess practicum students at BSW and MSW levels will be undertaken, whilst highlighting the challenges involved in assessing readiness to practice. Finally, we examine the gendered nature of social work practicum and offer some recommendations for the future.

The Social Work Practicum Manual at the department of social work at the UAEU emphasises that the importance of field placement is to promote a competent professional and a unique partnership between the department, the University, and the practice organisations. Also, the manual which is revised and reissued annually, states that the purpose of the practicum courses is to support the adaptability of students in the placement organisations and to provide them with the necessary framework to enable them to reflect critically on their own practice and on other people's practice (Department's of social work Practicum Manual, 2020). This reflection is supposed to help them understand the duties and responsibilities of social workers.

Field placement aims at a thorough understanding the specific needs of clients, the relevant policies, methods, and technologies used by the social worker along with participation in specific social work and administration tasks. (Goian, 2013 pl78)

32 J. of Practice Teaching \& Learning 17(3), pp.31-46. @ w\&bb 


\section{History of social work in the Arab World and the Middle East}

For the last two decades, most Arab Muslim countries worked on contextualising their social work programs to local needs. Moreover, they practice with an Islamic orientation to social work to correct the perceived bias against religion in social work profession (Al-Krenawi, 2003). Like most major world religions, many of Islam's core values and purposes are largely congruent with the mission, vision, and core values of the social work profession. It is important to note that Islam is not only a belief system but also a way of life that unifies metaphysical and materialistic dimensions (Hodge, 2005). Identifying as a Muslim typically indicates agreement with a common set of values or beliefs regarding the nature of the person and their relationship with others and with Allah. It is widely accepted that the five pillars of the Islamic worldview are commonalities that all Muslims share and are a foundation of a meaningful existence. Indeed, these accepted values are also social work values that may be operationalised in the empowerment model of helping, including in clinical settings. Al-Krenawi and Graham (2003) discovered that Muslim clients found that the solutions to their problems were based on religion (Al-Krenawi \& Graham, 2003) and religious values and practitioners have incorporated social work practice with specific aspects of Islam (Al-Krenawi \& Graham, 2000; Barise, 2005) with successful outcomes.

\section{Social work practice in the United Arab Emirates}

The government of the United Arab Emirates has developed a range of initiatives to enhance and sustain the wellbeing of its citizens and residents (Sloan et al, 2017). These initiatives include free healthcare, financial aid, benefits, interest free loans and free education from early childhood through University.

While the UAE is a country that is not characterised by extreme poverty such as the poverty-related problems found in other Arab countries, a new legal context requires systems transformation to address issues such as child abuse and neglect. The passage of a new child abuse law, crafted as a reaction, in part, to a high profile/extreme child abuse case in which one child died and a second child (a sibling) was seriously harmed. Outlined in

33 J. of Practice Teaching \& Learning 17(3), pp.31-46. ๑ wE्b 
this legislation is the requirement for child protection caseworkers to carry out investigations and treatment. As law was officially passed at the time of this writing and strategic workforce planning is not yet clear. However, the UAE has made child abuse response a priority and rolling out the system in a timely manner inevitably will reflect this fact. Research has already been conducted and that evidence will be important as detailed planning commences (Sloan, 2017).

The largest employer of social workers in the UAE is the federal government which employ social workers in nurseries, primary and secondary schools across the Emirates. In schools, social workers have undertaken tasks such as attendance monitoring, behaviour management, dealing with exclusions and punishments as well as working with people with special needs. Punishments in schools may include not allowing children to go on break or asking them to go to the social work office to engage with the social worker on specific interventions.

The UAE provides a number of services in the community such as the Family Development Center and The Social Support Center which employ social workers to engage with individuals and families in the community. In addition, some police departments in the UAE are sending their staff to undertake the social work programme and so it is logical to conclude that there is a growing need for this specialism in public protection services. For example, research by Kuyini, Powell and Nair (2020) concluded that social workers in the UAE were also employed in hospitals, corrections, and rehabilitation centers for psychiatric and other disabilities.

\section{Social work education in United Arab Emirates}

The United Arab Emirates University (UAEU) was established by Sheikh Zayed Bin Sultan Al Nahayan in 1976. Since that time, it has grown from the original four colleges to ten and educates approximately 12,000 students per year (UAEU, Online). The UAE University is Government supported and free to all Emirati nationals. Social work started as a minor programme in 1977 for Sociology majors. As a minor, it generated student interest to the extent that in 1986 the Social Work major was designed and implemented using social work models from Egypt and other Middle East countries such as Jordan and Kingdom of Saudi Arabia.

The first bachelor of social work program was established in 1994 at United Arab Emirates University and a master of social work program was

34 J. of Practice Teaching \& Learning 17(3), pp.31-46. @ wE-b 
established in 2013. The BSW program at UAEU is conceptualised along Islamic principles of social solidarity, cooperation and mutual aid within an ecological/strengths perspective with a focus on the traditional Arab Muslim family and the multicultural international populations (College of Humanities and Social Sciences, United Arab Emirates University, 2016). The BSW at UAEU program has matriculated well over 1,000 Bachelor of social work graduates (Al Bahar, 2011; Sloan, et al., 2017). It should be noted that the UAE social work curriculum has been aligned with a national qualifications' framework (United Arab Emirates National Qualifications Authority, 2017).

The UAE government has a national strategic plan for education of its citizens based on a social development model. One of the clear strengths of the UAE is the fact that the country boasts a network of universities and colleges with different initiatives in educating the social service workforce. Already functional, both the UAE University (Al Ain) and the Higher Colleges of Technology (Abu Dhabi \& Fujairah campuses) have Bachelor of Social Work programs based on the generalist practice model (United Arab Emirates University, 2016). Other programmes in human services education is taking place across the country. Currently, those educational programs do not offer degree programs in social work. For example, the Department of Sociology in the faculty of Arts and Humanities and Social Sciences at the University of Sharjah offers a BA degree in sociology that includes some topics of relevance to Social Work topic. Other universities offer a series of human services, family studies and related curricular (Sloan, 2017. In addition to three Emirati faculty members at the UAEU, the department currently comprises faculty from Jordan, the Kingdom of Saudi Arabia, United States of America and the United Kingdom.

As the UAE's first and most comprehensive residential university, the UAEU is committed to excellence in undergraduate and graduate education, research, and service to the nation and beyond. Through a student-centered educational experience, the University develops the intellectual, practical, creative and leadership abilities of the nation's men and women while enhancing cultural, social, and economic growth (UAEU, Online).

\section{Practicum at Social Work Department in UAEU}

There appears to be a gap between what students learn in social work

35 J. of Practice Teaching \& Learning 17(3), pp.31-46. @ w\&b 
classrooms and what they do in the placement internships (Soliman,2013).

This gap appears to exist elsewhere in relation the how students integrate theory into their practice. For example, in the United Kingdom, Maclean and Harrison (2015) examine this very concern and offer a range of models and resources to support students learning on placement.

In the Department of Social Work at UAEU, the BSW Field Practicum I and Field Practicum II are where students demonstrate their professional behaviors and ability to apply to their direct practice, the knowledge, values, ethical principles, and skills acquired in the classroom. The goal of the practicum courses is to provide a structured educational experience in an approved social service agency with an approved field instructor based upon a written learning contract. Students complete a variety of learning tasks that demonstrate practice behaviors and competencies of a beginning generalist social work professional.

With the exception of a few students, the majority of students on the MSW have a BSW which is the qualification needed to practice as a social worker in the UAE. However, they are undertaking the MSW to enhance their chances of employability. Whilst there is no shortage of employment for social work graduates in the UAE, female graduates are less mobile and are usually not able to take up employment in cities outside their own hometowns due to cultural and religious reasons. Consequently, holding a post graduate degree increases the range of jobs available to them and enhances opportunities for promotion. The current MSW also affords students the opportunity to specialise in Mental health or Criminal Justice. There are plans to include a Child \& Family specialism in the MSW in the future. For those already in employment, MSW students can opt to undertake their 500-hour practicum in their work setting and are assessed using the same methods as the BSW, however a more detailed case study is required.

Prior to students going into placements, they must meet the eligibility criteria and attend a mandatory pre-field orientation programme.

\section{Eligibility for practicum}

Prior to making application for field practicum, students are expected to have completed prerequisite courses, as identified in the Social Work Student Handbook, including general studies courses and many of the courses in their junior year. Practicum at the UAEU occurs in what is

36 J. of Practice Teaching \& Learning 17(3), pp.31-46. @ w\&bb 
known as the senior years where students are near completing their studies. Students are required to enroll in the corequisite course, Professional Seminar, during the semesters in which they are taking field practicum.

The Social Work Program does not grant prior learning or life experience credits as is the case in some programmes around the world.

The Social Work Student Handbook provides a list of recommended course sequencing, and complete course descriptions. Students are encouraged to meet with the Social Work Program Field Director or Social Work Program Director if there are questions regarding the requirements prior to application for Field Practicum (Social Work Students' Handbook, 2018).

\section{Pre-field \& orientation}

This is a three-day workshop which examines ethical dilemmas and ethical decision-making, Social Work Code of Ethics, professional behavior, skills for working in organisations, use of supervision, field instruction policies and procedures. Field instructors (practice educator) and students complete written learning agreements with identified tasks that allow the measurement and assessment of student attainment and competencies applied in agency settings. Students complete 16 hours orientation with the assigned field agency.

There are two BSW Practicum courses the first of which is SWK 465 (Social Work Practicum I). The student is required to work 4 days per week in a field agency so they can complete 400 hours practicing in the field in their final year of social work education which equates to 200 hours a term. This usually occurs between January and April. Students are engaged in supervised, direct service activities that provide practice experience in the application of the theory, values, ethical principles, and skills acquired in the foundation areas. The mechanism for supporting the integration of students' class and field learning is the field journal presented in the required field seminar taken concurrently with the field practicum. The second period of practicum is SWK 470 (Field Practicum II) where students continue their field practicum experience 4 days per week in a field agency. As has already been mentioned, students are expected to complete 200 for practicum I and 200 hours for Practicum II which makes a total of 400 hours. During this time, they are expected to of demonstrate professional social work behaviors in all aspects of their practicum experience. A field

37 J. of Practice Teaching \& Learning 17(3), pp.31-46. @ wEb 
journal is required, and data gathered will be used to develop a case study for presentation in Capstone Seminar. MSW students must complete 500 hours in the field (August- December) to meet the requirements and consolidate their theoretical learning (Department's Practicum Manual, 2020). The difference in practice learning hours between the BSW and the MSW is currently under review, however the rationale for this is that it affords students the opportunity to concentrate their practicum on their area of specialism (Mental Health or Criminal Justice).

\section{Assessing practicum at the UAEU}

Assessment of social work students can safeguard both general, public, and professional standards, and service users (Cowburn, 2000). Yet, according to Shardlow and Doel (1996), it can be difficult to assess a student social worker's competence in practice because of the subjectivities inherent in some of these processes.

In this section, we outline the methods used by field instructors (Agency based) and the Field Director (University based) to assess and evaluate students' practice. Methods of measurement must be specific and clear because existing assessment methods used at the UAEU are still unable to assess students' behavior and attitude before and after the intervention they undertake with clients.

Students on social work practicum at the UAEU are assessed against the programme learning outcomes (PLOs). The nine PLOs are:

1. Applying theoretical knowledge gained in human behavior and social environment, social work practice, social policy, and social research courses to generalist social work practice.

2. Demonstrate orally and in writing the ability to apply the problemsolving method to case scenarios based on real life situations.

3. Conduct bio-psycho-social assessments, needs assessments, planning, and evaluation in relation to generalist social work practice.

4. Apply social work generalist practice theory and skills with individuals, families, groups, communities, and organizational leadership.

5. Apply critical thinking in their interventions with individuals, families, groups, organizations, and communities.

6. Demonstrate orally and in writing their ability to conceptualize and

38 J. of Practice Teaching \& Learning 17(3), pp.31-46. @ w\&bb 
implement a research study including data analysis and the use of Statistical package for the social sciences (SPSS).

7. Apply knowledge and field experience to develop and defend a researchbased case study on an issue and/or problem encountered in the field.

8. Model the professional and ethical behavior expected of entry-level social work professionals, including the use of supervision for accountability and improvement of practice.

9. Develop self-awareness and learning practice strategies through selfstudy using readings, practice experiences and reflection.

To assess whether students have met the PLO's, evidence from the following tasks is collected and used.

- Attendance

- Daily Journal entries

- Progress meetings \& evaluations

- Field supervisor evaluation

- Case studies

- Presentations and

- Online assessments

\section{Attendance}

Students are expected to comply fully with attendance requirements of practicum. A student is allowed legitimate absence of one day, that is six training hours, and if the student is absent for more than two days without an official excuse and without notifying the academic supervisor, they will be required to make up the missed day.

\section{Daily Journal of activities and tasks}

The students must submit a detailed daily report on the activities they undertake during the training hours and hand it over to the academic and field supervisor every week of training. Students often find this interesting but anxiety provoking, stemming in part from the students lack knowledge about the supervisors' role (Bahrick, 1991).

39 J. of Practice Teaching \& Learning 17(3), pp.31-46. ๑ w\&b 


\section{Progress meetings and Evaluation}

Field et. al (2014) argue that it is good practice to ensure students are fully aware of the requirements. Consequently, during the placement, the field director will meet with the student and field supervisor to discuss progress and any concerns. These meetings are necessary to understand the range of work the student is engaged in and identify any gaps in the students learning. Students use this opportunity to clarify the requirements for the end of placement portfolio of evidence.

These progress meetings often result in a final evaluation of students in practicum. The evaluation committee comprises the field director, field supervisor, and a faculty member from the department, all of whom are usually Arabic speaking.

\section{The Field Supervisor Evaluation}

The students are evaluated by field supervisors based on the following criteria: attendance and attitude, understanding the practicum requirements commitment to professional conduct, good communication, assessment and intervention skills and finally, the ability to coordinate, plan, implement and evaluate their work with clients.

\section{Case Studies}

A case study in this context refers to the write up of a clients' circumstances and concerns following a meeting or series of meetings between the student social worker and the client. There is a standardized format for case studies and students are encouraged to interview clients whilst using the opportunity to study, understand, diagnose, create an intervention plan. Using case studies, students' understanding of theories can be assessed. The case study is then presented to the academic supervisor two faculty members to discuss and provide feedback. Field supervisors often use case studies to generate discussions during supervision (Regher, 2013).

40 J. of Practice Teaching \& Learning 17(3), pp.31-46. @ w\&bb 


\section{Presentation and online assessment}

Maintaining fairness in social work practicum assessment can be controversial. Consequently, all work by practicum students is submitted online to minimise the discrepancy in grading standards among individual instructors. Students are required to submit a practicum portfolio comprising reflections, documents and all practice assignments and incidental learning. The academic supervisor grades the students on their adherence to international code of ethics, integration of knowledge in practice, professional practice and service delivery, performance in university, professionalism, field work learning and professional development (Department's Practicum Manual, 2020).

Current practice is that students receive a numerical grade for their practicum and experience has taught us that these grades are skewed to the higher grading bands of $\mathrm{A}$ and $\mathrm{B}$ grades.

\section{Practicum related challenges}

The challenges that practicum students face is around the resources to assist them practice social work professionally.

Many of the students are weak in written Arabic and because the Social work curriculum is delivered in English, students are not taught to complete forms in Arabic. This poses major challenges when they arrive at practicum and are expected to practice almost exclusively in Arabic. This often results in tensions between students and their field supervisors.

Another challenge practicum students face is the limited time in training. The 200 hours of Practicum I takes place in schools (Tedam, 2020) and the other 200 hours in any government organisation or social service. It is, however, our view that this is insufficient to become a competent practitioner as it equates to approximately 66 days of practice learning for a BSW student and 83 days for an MSW student at the UAEU. Students studying social work in the UK are required to undertake a minimum of 200 days (Social Work England Online), or in Australia, a minimum of 1000 hours (AASW, Online).

There are challenges related to practicum Organisations themselves which has already been mentioned. Privacy and the high levels of confidentiality in the organisation prevents practicum students from working closely with

41 J. of Practice Teaching \& Learning 17(3), pp.31-46. @ wEb 
clients. Some other organisations go as far disallowing practicum students to see, know the names, or have any information about clients who receive support or any kind of service at the organisation. Culture and religion are deeply rooted in the minds of both clients and social workers. Muslims may view psychological problems differently than other communities for example among some Arab Muslims, people with mental health problems are referred to being possessed by the Jinn or spirits (Sloan, 2017).

In relation to supervisors, practicum students are allocated only onsite supervisors. The UAE does not have a system of appointing external supervisors consequently some students will be supervised by non-social workers on both practicum I and II. The absence of experienced or social work qualified supervisors impacts on the assessment strategies and outcomes for students.

\section{Challenges with current practicum assessment strategies}

Although the social work field practicum methods which are used at the UAEU are diverse, they are still not sufficient to assess students' readiness for the world of practice in a holistic manner. There are many challenges associated with the current assessment strategies which will now be outlined.

As a department we need to respond to the challenges identified in this paper and consider alternative supervision and assessment models to enhance or replace our current approach. We support the view of Bogo (2013) who suggests the need for valid and reliable assessment methods for practicum students.

Historically, students have passed their practicum components with little difficulty or concern, and whilst the majority of students work diligently to achieve this, there are many that could have benefited from longer periods in practicum to finetune their skills and develop their confidence and competence in working with vulnerable clients and their families.

In addition, there is the need to exploit new technologies which requires creativity and the development of an expanded body of research in social work education (Regher, 2013). More use of technology to enhance students learning environment is also required.

On a positive note, the current system of assessment uses triangulation

42 J. of Practice Teaching $\&$ Learning 17(3), pp.31-46. @ w\&bb 
which according to Field et. al (2014), is one way of ensuring fairness across the assessment process due to the multiple assessment methods used.

Placements in schools require a more robust process so as to avoid what students have referred to as non -social work roles such signing off internal exclusions, thus creating a negative image of social work within the school system (Tedam, 2020).

\section{Recommendations}

One of the most important recommendations from this paper is the urgent need for an assessment model. Having analysed the models which exist elsewhere, we are drawn to the Transparency of Assessment in Practice Education (TAPE) model (Stone, 2018) designed to make the elements of assessment explicit in practice learning. The model outlines six Ws

- who assesses them

- when they are being assessed

- Why students are being assessed

- where assessment is taking place

- the way they are assessed and

- what activities other than performance and writing are being assessed (p 985).

The scope of this paper does not permit a comprehensive analysis of the TAPE model, however we believe that it holds much relevance for the practicum assessment strategy we envisage of our programme at the UAEU.

Another recommendation is to introduce information technology related innovations to current practice particularly around distance and online methods (Lee, 2007). This would go a long way to reduce the volume of work created by placement visits, in the absence of additional staffing resources. For example, the field director can arrange online meetings as well as create interactive tools to assist students navigate their practicum.

Last but not the least there is the need for further research in social work education and practice more generally and field education specifically in the United Arab Emirates.

43 J. of Practice Teaching \& Learning 17(3), pp.31-46. @ wEb 


\section{Conclusion}

In this paper, we have examined the current assessment of social work students in practicum in the United Arab Emirates University and acknowledged the importance of avoiding ambiguity in the assessment process.

Writing from our experiences of field education in the UAE and the United Kingdom, we make a bold claim that field education in its current form in the UAEU has yet to be recognised as social work educations 'signature pedagogy' (Wayne, Bogo \& Raskin, 2010). We are hopeful that the UAEU is uniquely placed to design and deliver a type of field education which is culturally and politically sensitive, aligns with Islamic values and fits the needs the 21st century social work practitioner in the United Arab Emirates. It is this distinct area of field pedagogy which the authors seek to contribute to by recommending a review of the concept, design and delivery of assessment practice in field placements at the UAEU.

\section{References}

AASW (2012) Australian Social Work Education and Accreditation Standards (ASWEAS). Online at https://www.aasw.asn.au/document/item/3553 [accessed on 30 May 2020]

Al Bahar, M. (2011) Social work education in the UAE: Local reality and global challenges. in S. Stanley (Ed.) Social Work Education in Countries of the East: Issues and challenges. Hauppauge, NY: Nova Science (pp. 563-578)

Albrithen, A. \& Briskman, L. (2015) Social Work Ethics in Saudi Arabia: An Exploration. The British Journal of Social Work, 45, 7, 2192-2209

Al-Krenawi, A., \& Graham, J. R. (2000) Islamic theology and prayer relevance for social work practice. International Social Work, 43, 3, 289-304. doi: $10.1177 / 002087280004300303$

Al-Krenawi, A., \& Graham, J. R. (2003) Principles of social work practice in the Muslim Arab world. Arab Studies Quarterly, 25, 4, 75-91

Bahrick, A. S., Russell, R. K., \& Salmi, S. W. (1991) The effects of role induction on trainees' perceptions of supervision. Journal of Counseling and Development: Jcd, 69, 5, 434-434

Barise. A. (2005) Social work with Muslims: insights from the teachings of islam. Critical Social Work, 6. https://doi.org/10.22329/csw.v6i2.5660

44 J. of Practice Teaching \& Learning 17(3), pp.31-46. @ w\&bb 
Bogo, M., Regehr, C., Katz, E., Mylopoulos, M., Logie, C., \& Regehr, G. (2013) Adapting objective structured clinical examinations to assess social work students' performance and reflections. Journal of Social Work Education

Cowburn, M., Nelson, P., \&Williams, J. (2000) Assessment of social work students: standpoint and strong objectivity. Social Work Education, 19, 6, 627-637

Damron-Rodriguez, J. A., Lawrance, F. P., Barnett, D., \& Simmons, J. (2006) Developing geriatric social work competencies for field education. Journal of Gerontological Social Work, 48, 1/2, 139-160

Department of Social Work / UAEU BSW Manual for Practicum Course, 2016 revised 2020 [Internal Communication]

Department of Social Work / UAEU MSW Manual for Practicum Courses, 2016 revised 2020 [Internal Communication]

Department of Social Work/UAEU Students Handbook. [Internal Communication] Department of Social Work / UAUE Study Reports 2016, 2019 [Internal Communication]

Field,P., Jasper,C., \& Littler,L. (2014) Practice Education in Social Work. Achieving Professional Standards. St Albans: Critical Publishing

Finch, J. \& Taylor, I. (2013) Failure to Fail? Practice educators' emotional experiences of assessing failing social work students. Social Work Education, $32,2,244-258$

Goian, C. (2013) Teaching Social Work Practice. Bucharest: Pro Universitaria

Hicks, S. (2015) Social work and gender: An argument for practical accounts. Qualitative Social Work, 14, 4, 471-487

Hodge, D. R. (2005) Social work and the house of islam: orienting practitioners to the beliefs and values of muslims in the united states. Social Work, 50, 2, 162-73

Kuyini,A.B., Powell, O.H., \& Nair, S.N. (2020) Social work students' attitudes, self-efficacy and concerns about clients with developmental and psychiatric disabilities in the United Arab Emirates. Social Work Education, Advance Access DOI: 10.1080/02615479.2020.1712351

Lee, T.Y. (2007) The use of information technology to enhance the quality of teaching and learning in social work practicum: an example from the city university of Hong Kong. Journal of Technology in Human Services, 25, 1-2, 123-126. https://doi.org/10.1300/J017v25n01_08

Maclean,S. \& Harrison, R (2015) Theory and Practice. A straightforward guide. Litchfield: Kirwin Maclean

Parker,J and Crabtree, S. (2014a) Fish Need bicyles: An exploration of the perception of male social work students on a qualifying course. British Journal of Social Work, 44, 2) 310-327

Shardlow,S and Doel,M. (1996) Practice Learning and Teaching. London: Macmillan

45 J. of Practice Teaching \& Learning 17(3), pp.31-46. @ wE-b 
Simpson,G. and Murr, A. (2013) The 'not yet competent' student: Exploring the narratives of failure. Journal of Practice Teaching and Learning, 11, 3, 118-134

Sloan, L.M., Bromfield, N., Matthews, J., \& Smith-Rotabi, K. (2017) Social work education in the Arab Gulf: Challenges and opportunities. Journal of Religion and Spirituality in Social Work: Social Thought, 36, 1-2, 199-214, DOI: 10.1080/15426432.2017.1311247

Sloan, L.M., Saleh, A., Al-Mannai, S., Al-Kaabi, I. \& Al-Kawari, K. (2010) Social work education in Qatar. in S. Stanley (Ed.) Social Work Education in Countries of the East: Issues and challenges. Hauppauge, NY: Nova Science

Social Work England (2020) Guidance on Practice Placements. Online at https:// www.socialworkengland.org.uk/standards/guidance-documents/practiceplacements-guidance/ [accessed on 30 May 2020]

Soliman, H. (2013) Social Work in the Middle East. New York: Routledge

Soliman, H. H. \& Elmegeid, H. S. A. (2010) The challenges of modernization and social work education in developing countries: The case of Egypt. International Social Work, 53, 1, 101-114

Stone, C. (2018) Transparency of assessment in practice education: the tape model. Social Work Education, 37, 8, 977-994

Tedam, P. (2020) Social distancing and social work field placements. Journal of Practice Teaching \& Learning, 17, 1, 51-56

The Social Work Department / UAEU Practicum Manual (2016 - 2020)

The UAEU Students Handbook, (2016 -2018)

United Arab Emirates National Qualifications Authority, 2017

Wayne, J., Bogo, M., \& Raskin, M. (2010) Field education as the signature pedagogy of social work education. Journal of Social Work Education, 46, 3, 327-339. doi:10.5175/jswe.2010.200900043

46 J. of Practice Teaching \& Learning 17(3), pp.31-46. @ w\&b 